\title{
Molecular Phylogeny of Ladybird Beetles (Coccinellidae: Coleoptera) Inferred from Mitochondrial 16S rDNA Sequences
}

\author{
A.G.B. Aruggoda, R. Shunxiang ${ }^{1}$ and Q. Baoli ${ }^{1}$ \\ Department of Agricultural and Plantation Engineering \\ Faculty of Engineering Technology \\ The Open University of Sri Lanka \\ Nugegoda, Sri Lanka
}

\begin{abstract}
Although ladybird beetles (Coccinellidae: Coleoptera) are charismatic and have great ecological and economic significance, understanding of the evolutionary history of Coccinellidae remains poor. Many hypothesis of evolutionary relationships based on morphological features have been proposed, but none have been verified using a formal phylogenetic analysis. The objectives of this study was to apply molecular evidence of $16 \mathrm{~S}$ rDNA to construct a molecular phylogeny for ladybird beetles, examining the monophyly of the tribes and several lower-level taxa within the group, and to establish basic phylogenetic patterns. 16S rDNA fragments were sequenced from 47 species of in-group and two species of out-group taxa. DNA data showed evidences of rapid evolution and saturation, having AT and transition at a higher level. $16 \mathrm{~S}$ rDNA gene region indicated the availability of phylogenetic signals with the presence of skewness with significant hierarchical structure as well as having higher number of parsimony informative characters. Trees were reconstructed using multiple methods and characters mapped on the topology via Neigbour Joining and Minimum Evolution methods. $16 \mathrm{~S}$ rDNA phylogenetic analyses were supported well on below tribe level relationships of the subfamilies. The genus level is prominent accumulating together the species belonging to same genus in all tribes. Results suggest that the molecular data provide robust support across the topology below tribe level and below genus level and that this topology provides important new insights as well as confirming the existing positions of the species in the evolution of the ladybird beetles.
\end{abstract}

\section{INTRODUCTION}

The Ladybird beetles are frequently used as research material in various fields of biological sciences, e.g. the evolutionary biology, population ecology, genetics, cytology and biogeography (Sasaji, 1971). The different classification systems have been used to classify the members of the family Coccinellidae depending on the taxonomists and many attempts have been made concerning the phylogenetic relationships among the subfamilies from different viewpoints. However, the subdivision of the family has given rise to much controversy.

Very few molecular studies have been reported on Coccinellidae, compared to other insect groups in the world. Kobayashi et al., (1998) investigated Cytochrome Oxidase I (COI) gene

1 Department of Entomology, College of Natural Resources and Environment, South China Agricultural University, Guangzhou 510642, China 
region of Epilachninae studying the relationships among several species focusing on host shifts. More recently, von der Schulenburg et al., (2001) found extreme lengths and length variation of Internal Transcribed Spacer Region I (ITS1) gene region of twelve species belonging to five subfamilies of Coccinellidae and reported that the extreme length variations of some species were due to internal repeats. High variability of the ITSI sequences was observed among tribes, genera and species.

The first research on molecular systematic analyses of family Coccinellidae was published by $\mathrm{Fu}$ and Zhand (2006) sequencing partial COI gene region to infer the higher taxonomic level relationships of sixteen species belonging to four subfamilies. These molecular studies of Coccinellidae have produced interesting outcomes about the hidden relationships among species which could not be resolved by the phenotypic studies or behavioral studies. 16S rDNA gene has been shown to be useful for examining insect relationships from the genus level to the family level (Hypša et al., 2002, Whitfield et al., 2002, Ribera et al., 2003). In the present study, the sequences of the $16 \mathrm{~S}$ rDNA gene of eight tribes belonging to six subfamilies of Coccinellidae as identified by the current phenotypic classification were investigated. The aim of this study was to use molecular characters to infer phylogenetic relationships within the Coccinellidae, constructing the phylogeny including the exemplar species representing tribes and subfamilies of the currently recognized lower taxa (genera, subgenera).

\section{MATERIALS AND METHODS}

\section{Taxon sampling, specimen identification and out-group selection}

Forty nine taxa (47 ingroup, 2 outgroup) were sampled in this study according to the present phenotic classification by Pang and Ren 2003. Phaedon brassicae and Galerucella birmanica (Family: Chrysomelidae) were selected and sequenced as out groups.

\section{DNA extraction, amplification, and sequencing}

For most samples, field collected tissues were stored in $95 \%$ ethanol, preserving whole bodies. DNA was extracted from either the thorax or the anterior abdomen of each single specimen using phenol:chloroform extraction procedure with some modifications. Tissue was grounded in an STE homogenization buffer, incubated for 2-3 hr with proteinase $\mathrm{K}$ at 60 ${ }^{\circ} \mathrm{C}$, followed by four phenol:chloroform extractions, ethanol precipitation and resuspension in TE buffer (10 mMTris, $1 \mathrm{mM}$ EDTA). Polymerase Chain reaction was carried out with 50 $\mu \mathrm{l}$ PCR reaction volumes. Each $50 \mu \mathrm{l}$ reaction mixture contained $0.5 \mu \mathrm{l}$ Taq polymerase TAKARA (5 units/ $\mu \mathrm{l}), 5 \mu \mathrm{l}$ 10x Taq buffer, $5 \mu \mathrm{l} \mathrm{Mgcl}(25 \mathrm{mM}), 4 \mu \mathrm{d}$ dNTP mixture $(25 \mathrm{mM})$, $2 \mu \mathrm{l}$ each primer $(10 \mu \mathrm{M}), 3 \mu \mathrm{l}$ of DNA extract and $28.5 \mu \mathrm{l}$ of doubled distilled water. $16 \mathrm{~S}$ rDNA, was amplified using the following program: (1) an initial denaturation of $5 \mathrm{~min}$ at 94 ${ }^{\circ} \mathrm{C}$; (2) $40 \mathrm{sec}$ at $94{ }^{\circ} \mathrm{C}$ denaturation, $40 \mathrm{sec}$ at $51^{\circ} \mathrm{C}$ annealing, and $40 \mathrm{sec}$ at $72{ }^{\circ} \mathrm{C}$ extension (35x); (3) a final extension of $10 \mathrm{~min}$ at $72{ }^{\circ} \mathrm{C}$. Amplified PCR products were gel purified with a Gel Purification Kit (TAKARA). PCR products were sequenced directly from two directions using ABI-3730 DNA sequencer with ABI Prism Big Dye cycle sequencing kit. The same primers were used for amplification and sequencing (Table 1). All sequences were deposited in the Gene Bank nucleotide sequence database (http://www.ncbi.nlm.nih.gov). Accession Nos. EU392357 EU392405. 
Table 1. Oligonucleotide primers (5'to 3') used for amplifying and sequencing of species belonging to family Coccinellidae.

\begin{tabular}{lll}
\hline Name & \multicolumn{1}{c}{ Sequence } & \multicolumn{1}{c}{ Source } \\
\hline LR-J-12887 & 5' CCGGTCTGAACTCAGATCACGT 3' & Simon et al., 1994 \\
LR-N-13398 & 5' CGCCTGTTTAACAAAAACAT 3' & Simon et al., 1994 \\
CPD264-1 & 5' GCCTGTTTATCAAAAACAT 3' & Long and Pang 2003 \\
16SF2 & 5' GGCCTGCCCACTGAVVTT 3' & Present study \\
16SF5 & 5' TTTXAAGGGCCGCAGTAT 3' & Present study \\
CPD264-2 & 5' CCGGTCTGAACTCAGATCA 3' & Long and Pang 2003 \\
\hline V=T/A, X=G/A & &
\end{tabular}

\section{Alignment of nucleotide sequences and phylogenetic analysis}

All the sequences were aligned using Clustal W program: a sub program of MEGA 4.0 (Tamura et al., 2007) and the alignment was refined manually where necessary. Base frequencies, pair wise nucleotide sequence divergence and molecular character statistics were calculated for each gene fragment using MEGA 4.0 (Tamura et al., 2007). NeighborJoining (NJ) and Minimum-Evolution (ME) implemented in MEGA 4.0 (Tamura et al., 2007) for the phylogenetic construction.

\section{RESULTS AND DISCUSSION}

\section{Sequence variation}

16S rDNA gene region was analyzed in order to infer phylogenetic relationship of family Coccinellidae. When gaps were added to the alignment, 415 bases were analyzed. Length variations of the partial 16S rDNA sequences among taxa ranged from 381 to 407 bases. Of the 415 bases examined, 186 bases were parsimony informative. 16S rDNA gene region indicated the availability of phylogenetic signals having higher number of parsimony informative characters, 186/415. The average nucleotide composition proportions for the Coccinellidae sequences were: G, 14.5; A, 37.6; T, 40.6; and C, 7.3. These results agree with the findings of the 16 rDNA region of other insect species showing a bias towards adenine and thymine which was consistent with the base composition of the corresponding $16 \mathrm{~S}$ rDNA region (Vogler and Pearson 1996, Han and McPheron 1997). Variable sites were not randomly distributed over the examined $16 \mathrm{~S}$ rDNA region, and nucleotide divergence patterns of this gene showed that there were highly variable regions. This result suggests that substitution patterns might be constrained by the function of the gene. According to Avise (1994) this is due to maternal heredity of mitochondrial genes. The pattern of substitutions showed the greatest bias with $\mathrm{A} \longleftrightarrow \mathrm{T}(43 \%)$, which was larger than changes of $\mathrm{A} \longleftrightarrow \mathrm{G}$ $(9 \%), \mathrm{T} \longleftrightarrow \mathrm{C}(3 \%)$, and $\mathrm{T} \longleftrightarrow \mathrm{G}(5 \%)$, while changes of $\mathrm{A} \longleftrightarrow \mathrm{C}(1 \%)$ and $\mathrm{G} \longleftrightarrow \mathrm{C}(0 \%)$ were rare. Similar results have shown in analysis of same gene regions in Drosophila species (Desalle et al., 1987). According to the suggestions made by Desalle et al., (1987) this condition is due to silent transversions of AT, where the insects can occur are subject to fewer adaptive constraints than are transitions that lower the $\mathrm{A}+\mathrm{T}$ content. In order to evaluate the phylogenetic information of sequence regions selected, transitions and transversions were plotted separately against JC69 for the variable regions of 16S rDNA gene to detect the possible saturation (Fig. 1). Transitional substitutions in the 16S rDNA 
showed a heavy degree of saturation, thereby suggesting a large amount of convergence in this region among distant taxa. On the other hand, saturation plots and divergence estimates indicate that the $16 \mathrm{~S}$ ribosomal gene fragments show evidence of rapid evolution and saturation, having AT and transition at a higher level.

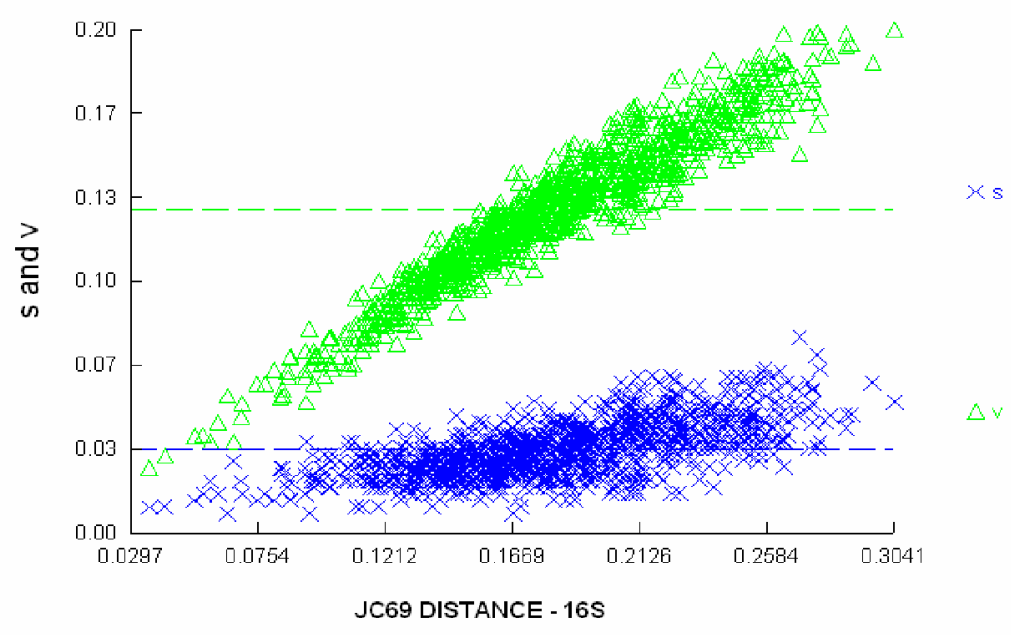

Fig. 1. Saturation plots of the number of substitutions for 16S rDNA vs. JC69 genetic distance.

This result is in accordance with Misof et al., (2001) and Eisuke and Etiiti (2006) who experimented higher taxonomic levels of other insect groups with 16S rDNA. The number of base substitutions per site from analysis between sequences were among the ingroup taxa. The highest sequence divergence was detected as $28.6 \%$ between Axinocymnus species of subfamily Scymninae. With the outgroup Chysomelidae family species $16 \mathrm{~S}$ rDNA maintained the highest and average genetic distance levels of $29.2 \%$ and $18.9 \%$ respectively.

\section{Phylogenetic analysis}

The Permutation Tail Probability (PTP) test was conducted and the results $(\mathrm{P}<0.01)$ suggest that a significant hierarchical structure exists in the molecular data set with the presence of skewness. The Neighbor Joining (NJ) trees and Minimum Evolution (ME) trees contributed low as well as high bootstrap values of 16S rDNA gene region. 16S rDNA phylogenetic analysis supported below tribe level relationships of the subfamilies. Therefore, the phylogenetic relationships were discussed concerning tribe level classification rather than subfamily levels. The genus level was prominent, accumulating together the species belonging to genera in all tribes. However, supported bootstrap values for several branches above tribe level relationships were weak, suggesting that further studies are required for better understanding. However tribe Psylloborini was prominent. Tribe Hippodamiini was not visible with the species Hippodamia potanini being clustering together with the tribe Coccinellini with relatively high bootstrap values (Fig. 2 and 3). Moreover, further studies are required adding more number of species at the tribe as well as genus level to clarify the position of tribe Hippodamiini. The species more than one under a single genus; Oenopia, Harmonia, Coccinella, Lemnia and Micraspis confirmed their positions in the relevant genera in the analysis with considerable higher bootstrap values. A close relationship 
between Synonycha grandis and Megalocaria dilatata, the species representing the Synonycha and Megalocaria genera were supported by high bootstrap value: 72 in ME analysis. Propylea japonica relationship with the genus Lemnia was supported with low bootstrap value in ME as well as NJ analysis. Further verification is required at genus level.

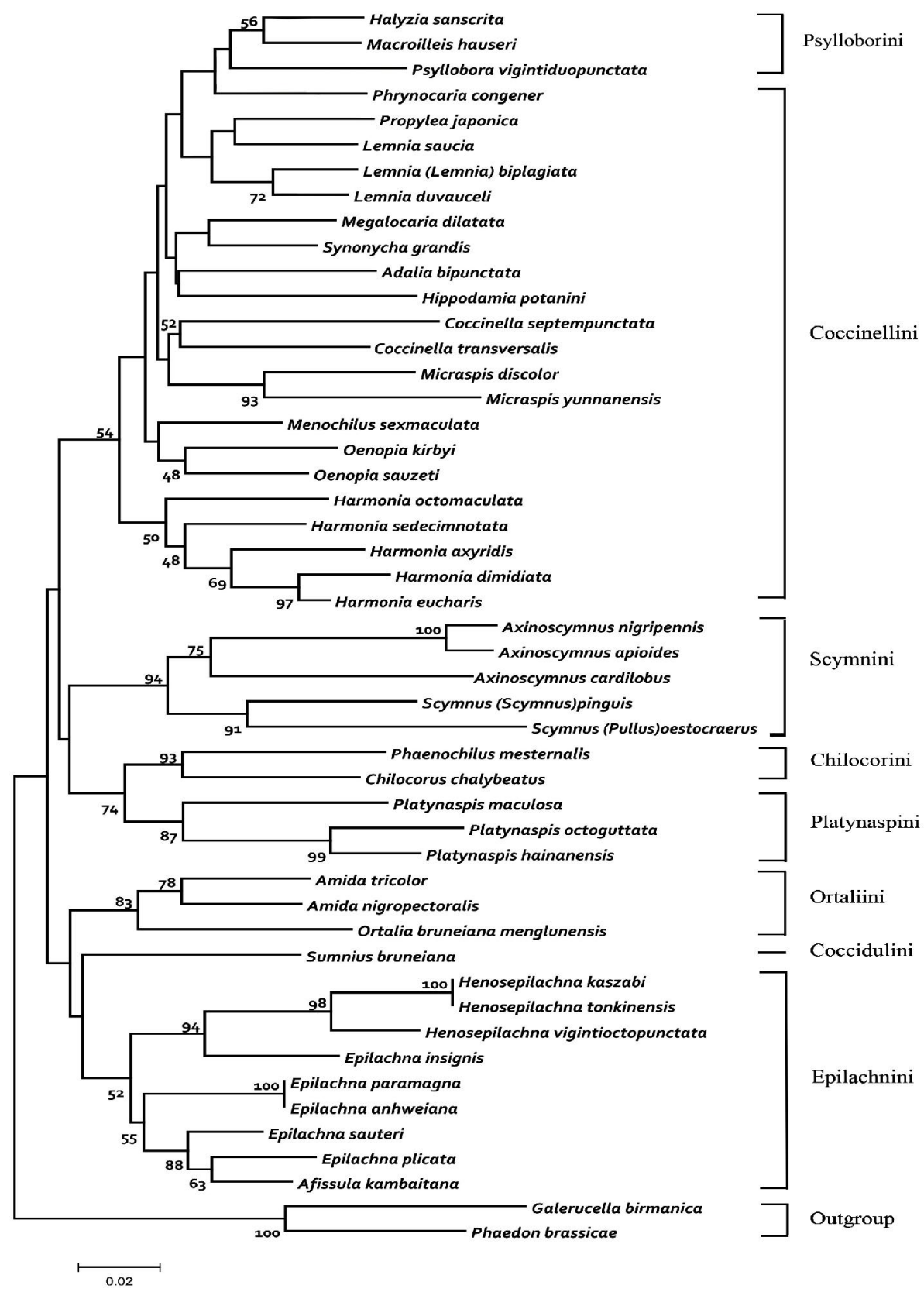

Fig. 2. Minimum evolution bootstrap phylogeny of family Coccinellidae inferred from16S rDNA sequences. Bootstrap probabilities are shown near the nodes. 
Aruggoda et al.

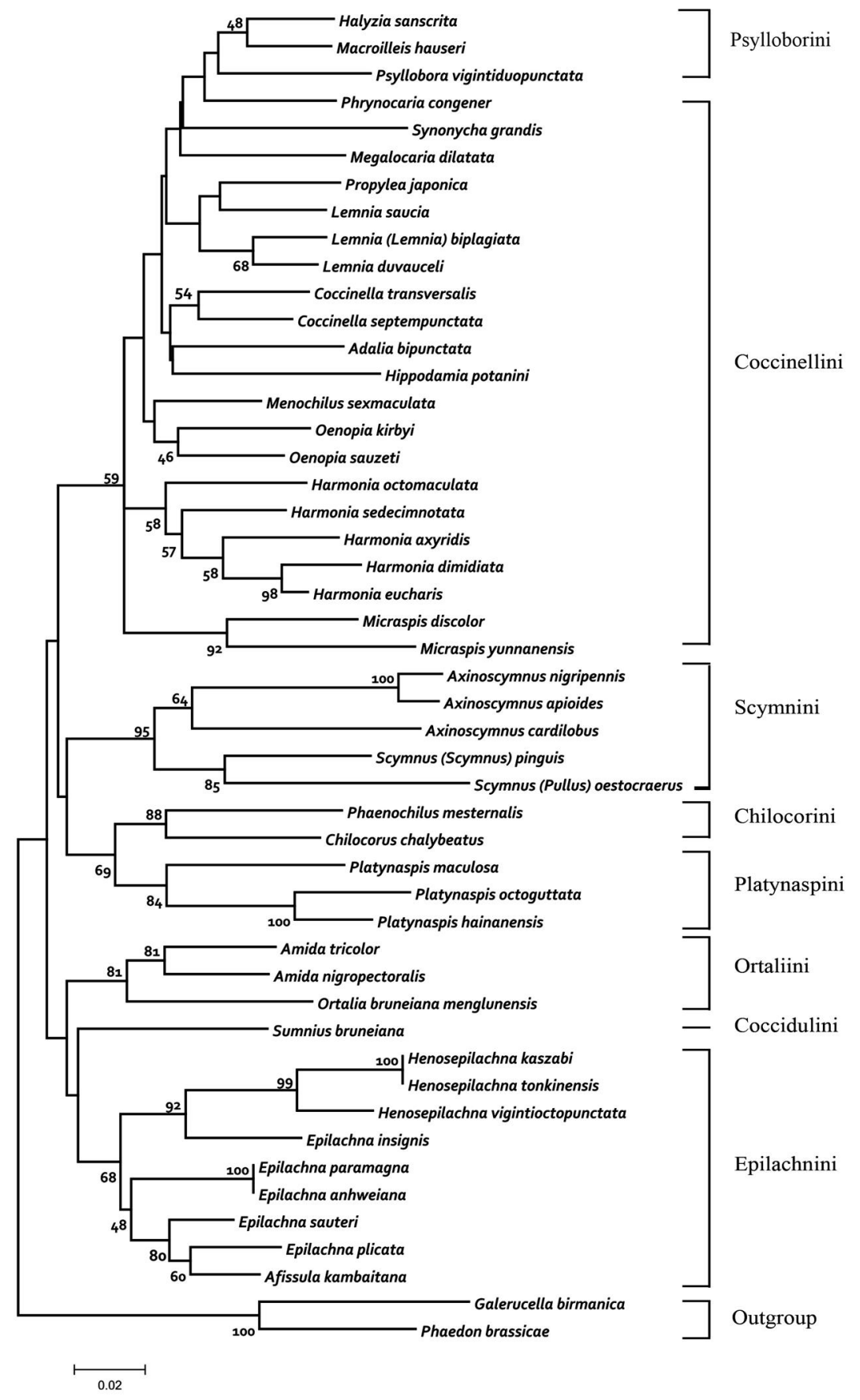

Figu. 3. Neighbor Joining bootstrap phylogeny of family Coccinellidae inferred from 16S rDNA sequences. Bootstrap probabilities are shown near the nodes. 
Tribes Scymnini, Chilocorini and Platynaspini showed closer relationship with tribes Coccinellini and Psylloborini in both analysis. Genus Scymnus and genus Axinosscymnus were supported by $>94$ bootstrap value and were well established within the Tribe Scymnini. Chilocorus and Phaenochilus genera showed closer relationship supporting >69 bootstrap value in all two analyses confirming their positions within the Tribe Chilocorini. Monophyly of tribe Ortaliini and Epilachnini were well supported in both analyses of 16S rDNA sequences. However, the results did not resolve the exact position and relationships in the tree due to low bootstrap values. Amida and Ortalia genera were nested with high bootstrap values within tribe Ortaliini in all analyses. The large tribe of Epilachnini nested three genera, Henosepilachna, Epilachna and Affisula. Epilachna as well as Henosepilachna were not monophyletic. However, the correct relationship of tribe Coccidulini representing subfamily Coccidulinae to other analyzed tribes were not resolved, since the tribe includes only one species. Some important characters of tribe Eplilachnini were common with the tribe Ortaliini and were not connected with the Scymnini - Chilocorini, Platynaspini stock. The tribe Coccidulini is closely related to the tribe Ortaliini (Fig. 2 and 3). The positions of Scymninae and Cholocorinae subfamilies together with subfamily Coccinellinae tallied with the results of the previous studies (Fu and Zhand, 2006 and von der Schulenburg et al., 2001).

\section{CONCLUSIONS}

The results of the present study indicated that the subfamily Epilachninae consisting of a single tribe Epilachnini, is distantly related to tribes of subfamily Coccinellinae. This has been long considered by many taxonomists. The subfamily Epilachninae consisted of one large tribe showing close affinity to the tribes of Coccinellini and Psylloborini of the subfamily Coccinellinae. Therefore, the place of Epilachninae in the tree of classification must be closer to the subfamily Coccinellinae (Sasaji, 1971). The relationship between subfamily Scymninae and tribe Ortaliini was debatable during the past few decades. The present study separated the tribe Ortaliini from tribe Scymnini, positioning tribe Chilocorini in between. This does not support the statement "tribe Ortaliini of subfamily Ortaliinae must be placed closer to the tribe Scymnini". This has been long on debate among taxonomists until the Gordon's reconstruction of the family classification in 1976 and 1985, separating Ortaliinae into an individual subfamily. Present study did not include species of tribes from subfamily Sticholotinae which is considered as the most primitive group in the family Coccinellidae and species from subfamilies of Lithophilinae, Aspidimerinae and Hyperaspinae (according to the Gordon's phenotic classification 1976, 1985). Due to this reason the phylogenetic relationship of the entire family is not resolved. The inclusion of all phenotypically identified subfamilies with more than one species for each genus and with more than one genus for each tribe is a must to obtain a better understanding of the subfamily level relationships. At the same time, investigations of morphological and ecological characteristics based on new evidence of the present phylogenetic study and incorporation of those characters with DNA sequence data are necessary in order to understand the complete phylogeny of family Coccinellidae.

\section{ACKNOWLEDGMENTS}

We are indebted to Professor Chen Luo and Professor (Ms.) Shuo-Yang Wen for accepting this study to be carried out in the Laboratory of Molecular Evolution, Department of Entomology, College of Natural Resources and Environment, South China Agricultural University, Guangzhou, China. 


\section{REFERENCES}

Avise, J.C. (1994). Molecular Markers, Natural History and Evolution, Chapman and Hall, New York, NY, 511 pp.

Desalle, R., Templeton, A., Mori, I., Pletscher, S. and Johnston, J.S. (1987). Temporal and spatial heterogeneity of mtDNA polymorphism in natural populations of Drosophila mercatorum. Genetics 116:215-223.

Eisuke, H. and Eiiti, K. (2006). Phylogenetic analysis of the insect order Odonata using 28S and 16S rDNA sequences: a comparison between data sets with different evolutionary rates. Entomol. Sci. 9(1):55-66.

Fu, J. and Zhand, Y.C. (2006). Sequence analysis of mtDNA - COI gene and Molecular Phylogeny on twenty seven Species of Coccinellids (Coleoptera: Coccinellidae). Entomotaxonimia. 28(3): 179-185.

Gordon, R.D. (1976). The Scymnini (Coleoptera: Coccinellidae) of the United States and Canada: Key to genera and revision of Scymnus, Nephus and Diomus. Bulle. of the Buff. Soc. of Nat. Sci. 28: 1-362.

Gordon, R.D. (1985). The Coccinellidae of America North of Mexico. J. New York Entomol. Soc. 93(1): 1-912.

Han, H.Y. and McPheron, B.A. (1997). Molecular phylogenetic study of Tephritidae (Insecta: Diptera) using partial sequences of the mitochondrial 16S ribosomal DNA. Mol. Phylogenet. Evol. 7:17-32.

Hypša V., Tietz, D.F., Zrzavy, J., Rego, R.O., Galvao, C. and Jurberg, J. (2002). Phylogeny and biogeography of Triatominae (Hemiptera: Reduviidae): molecular evidence of a NewWorld origin of the Asiatic clade. Mol. Phylogenet Evol. 23: 447-457.

Kobayashi, N., Tamura, K., Aotsuka, T. and Katakura, H. (1998). Molecular phylogeny of Twelve Asian Species of Epilachnine Ladybird Beetles (Coleoptera: Coccinellidae) with notes on the Direction of host shifts. Zoological Sc. 15: 147 - 151.

Long, J. and Pang, H. (2003). Polymerase Chain Reaction on 16S rDNA of Coleoptera: Coccinellidae. J. of Guizhou Normal University (Natural Sciences). 21(2): 52-58.

Misof, B., Rickert, A. M., Buckley, T.R., Fleck, G. and Sauer, K.P. (2001). Phylogenetic signal and its decay in mitochondrial SSU and LSU rRNA gene fragments of Anisoptera. Mol. Biol. Evol. 18: 27-37.

Pang, X.F. and Ren, S. (2003). Biology, ecology, taxonomy and distribution of the Chinese species of Coccinellidae. P.R.China. 1-168pp.

Ribera, I., Bilton, D.T. and Vogler, A.P. (2003). Mitochondrial DNA phylogeography and population history of Meladema diving beetles on the Atlantic Islands and in the Mediterranean basin (Coleoptera, Dytiscidae). Mol. Ecol. 12(1): 153-167. 
Sasaji, H. (1971). Fauna Japonica: Coccinellidae (Insecta, Coleotpera). Acad. Press, Tokyo, Japan, 340 pp.

Simon, C., Francesco, F., Andrew, B., Bernie, C., Hong, L. and Paul, F. (1994). Evolution, Weighing and Phylogenetic Utility of Mitochondrial Genes Sequences and a Compilation of Conserved Polymerase Chain Reaction Primers. Annals of the Entomol. Soc. America, 87(6): 651 - 701.

Tamura, K., Dudley, J., Nei, M. and Kumar, S. (2007). MEGA 4: Molecular Evolutionary Genetics Analysis (MEGA) software version 4.0. Mol. Biol. Evol. 24(8):1596-1599; doi:10.1093/molbev/ msm092.

Vogler, A.P. and Pearson, D.L. (1996). A molecular phylogeny of the tiger beetles (Cicindelidae): congruence of mitochondrial and nuclear rDNA data sets. Mol. Phylogenet. Evol. 6: 321-338.

von der Schulenburg, J.H.G., Hancock, J.M., Pagnamenta, A., Sloggett, J.J., Majerus, M.E.N. and Hurst, D.D. (2001). Extreme length and length variation in the first ribosomal Internal transcribed spacer of ladybird beetles (Coleoptera: Coccinellidae). Mol. Biol. Evol. 18: $648-660$.

Whitfield, J.B., Mardulyn, P., Austin, A.D. and Dowton, M. (2002). Phylogenetic relationships among Microgastrine braconid wasp genera based on data from the 16S, COI, and 28S genes and morphology. Syst. Entomol. 27: 337-359. 